\title{
Quantitative measurement of bubble textures in pumice clasts using a digital stereo microscope with low-angled ring illumination
}

\author{
Masatoshi Ohashi1 ${ }^{1,2^{*}}$, Mie Ichihara ${ }^{2}$, Fukashi Maeno ${ }^{2}$, Ben Kennedy ${ }^{3}$ and Darren Gravley ${ }^{3}$
}

\begin{abstract}
Quantitative analysis of bubble textures in a large number of volcanic pyroclasts is critical to investigating the eruption dynamics in a volcanic conduit. Here, we used a digital stereo microscope with low-angled ring illumination (DSM-LaRI) to measure bubble textures on unpolished cutting surfaces of pumice clasts. As the DSM-LaRI enhances brightness contrast between the bubbles (pores) and the matrix, we easily obtained the two-dimensional data on the size and shape of bubbles by image analysis. The DSM-LaRI imaging provided the distributions of size and shape of bubbles at least $50 \mu \mathrm{m}$ across. We applied the DSM-LaRI to analyze more than 1000 pumice clasts from the $232 \mathrm{AD}$ Taupo eruption and measured the mean bubble radius $(\bar{R})$ and the mean deformation degree $(\bar{D})$ in the individual clasts. The distribution of $\bar{R}$ and $\bar{D}$ in each layer showed a distinctive difference between the fallout and the flow deposits. These quantitative data are consistent with a qualitative classification in a previous study. Although the new DSM-LaRI method has the disadvantage of the low spatial resolution, it allows for the analysis of a large number of pumice clasts in a short time, which can address larger scale heterogeneity, by efficiently generating a large representative suite of bubble size and shape data to link bubble textures to conduit processes. This provides vital information for quantitatively modeling eruption dynamics.
\end{abstract}

Keywords: Bubble texture, Pumice, Bubble size, Deformation degree, Digital stereo microscope

\section{Introduction}

Bubble textures in eruptive products have been used to infer magmatic processes occurring before, during, and immediately after the eruption. For instance, the bubble number density can be converted to the decompression rate during magma ascent (Toramaru 1995, 2006), and the bubble shape can preserve records of strain rate and shear stress (Rust et al. 2003; Rust and Cashman 2007). The analysis of bubble textures has become an essential research method to reveal the intra-conduit processes during an eruption.

The most common approach to characterize bubble textures is two-dimensional (2D) observation on thin

\footnotetext{
*Correspondence: ohashi.masatoshi.582@m.kyushu-u.ac.jp 1 Department of Earth and Planetary Sciences, Kyushu University, Motooka, 744, Nishi-ku, Fukuoka-shi, Fukuoka 819-0395, Japan Full list of author information is available at the end of the article
}

sections and grain mounts (Klug and Cashman 1994; Klug et al. 2002; Shea et al. 2012). Thin-section images taken by a scanning electron microscope (SEM) provide textural information that can be later used to obtain bubble number density and bubble size, in $2 \mathrm{D}$. Then, the data are stereologically converted into 3D textures. This approach has the advantage of high spatial image resolution and can accurately capture the size and shape of microscale bubbles with circular to elliptical shapes. However, the stereological conversion of 2D to 3D data is challenging for elongated polydisperse bubbles, because a cutting section rarely passes through the bubbles' most volumetrically representative parts and the probabilities that a section intersects the individual bubbles cannot be derived analytically (Shea et al. 2010). Recently, the use of $3 \mathrm{D}$ imaging by X-ray computed tomography $(\mathrm{CT})$ is increasing in bubble texture analyses on pyroclasts (e.g., Gurioli et al. 2008; Polacci et al. 2010; Giachetti et al. 
2011). This approach can accurately visualize bubble textures in 3D. The recent development of high-resolution tomography technique allows us to resolve very thin glass walls of around $1 \mu \mathrm{m}$ (Degruyter et al. 2010; Dingwell et al. 2016; Fauria et al. 2017). However, subsequent complex coalescence of bubbles, and relaxation of glass can produce irregular bubble networks inappropriate for bubble size distribution analysis (Kennedy et al. 2016).

Along with the microscale bubbles described above, pheno-bubbles (Toramaru 2014), which are large bubbles visible to human eyes, have been studied in recent decades. The macroscopic classification of the pyroclasts based on the visual observation of the pheno-bubbles is helpful to get a general view of bubble textures in an eruption. For example, the stratigraphic change of the relative abundance of tube pumice (consisting of tubelike bubbles) was interpreted to be the result of the temporal evolution of magma ascent velocity and the conduit diameter (Taddeucci and Wohletz 2001). The coexistence of tube pumice and spherical pumice (consisting of almost spherical bubbles) in the same unit has some implications for the velocity distribution across a conduit (Polacci et al. 2001, 2003) and for the conduit diameter (Mitchell et al. 2019). The relative abundance of glass shards, i.e., fragments of large bubble walls, is a useful clue to distinguish the fragmentation mechanism between magmatic and phreatomagmatic eruptions (Hiroi and Miyamoto 2016).

Although the macroscopic classification is now commonly used to observe bubble textures in eruption deposits (Taddeucci and Wohletz 2001; Polacci et al. 2003; Houghton et al. 2010), it has the disadvantage of relying on qualitative classification, which may vary from person to person. In addition, the boundaries between pyroclast types are frequently gradational. Digital image analyses are useful for objective classification, but it is technically unrealistic to apply imaging by SEM or X-ray CT to a large number of pyroclasts for obtaining a distribution of bubble textures. Making thin sections for SEM is timeconsuming work, and analyzing bubble textures by $\mathrm{X}$-ray $\mathrm{CT}$ is also time consuming especially when resolving thin bubbles walls. The latter technique is not cheap and not overly common, either. For density measurement, it has been recommended to analyze at least 100 pumice clasts to characterize a layer (Shea et al. 2010; Houghton and Carey 2015). To get a quantitative distribution of bubble textures of the whole deposit, an efficient method of digital image analysis is required.

In this study, we develop a method of quickly analyzing visible-size bubbles from unpolished cutting surfaces using a digital stereo microscope with a low-angled ring illumination (hereafter termed DSM-LaRI). It allows us to analyze bubble textures of a statistically sufficient number of pumices (an order of a thousand). We apply the technique to the $232 \mathrm{AD}$ Taupo eruption products, consisting of a variety of bubble textures (Houghton et al. 2010). Comparing the 2D data by DSM-LaRI with those by SEM and the 3D data by X-ray CT, we evaluate the significance and limitations of the new method.

\section{Materials}

\section{The 232 AD Taupo eruption}

The 232 AD Taupo eruption in New Zealand is a good test case for measuring a wide variety of bubble textures statistically and stratigraphically. The reasons are that its pyroclasts are well preserved and the eruption stratigraphy/chronology is well constrained (Wilson and Walker 1985). This eruption, which ejected phenocryst-poor rhyolite of $35 \mathrm{~km}^{3}$ DRE, was one of the largest rhyolitic eruptions in the world in the last 5000 years (Wilson and Walker 1985). It formed seven units of eruption products from at least three vents within Lake Taupo (Smith and Houghton 1995). The eruptive products include three phreatomagmatic fall deposits (units 1, 3, 4), Hatepe plinian fall deposit (unit 2), Taupo plinian fall deposit (unit $5 a$ ), pyroclastic flow deposit (unit 5b), Taupo ignimbrite (unit 6), and the late-stage dome (unit 7) (Houghton et al. 2003). While magma composition appears homogeneous throughout, the great diversity of eruption styles is attributed to purely physical processes in the eruption, such as magma-water interaction and vent migration (Houghton et al. 2003, 2010).

Houghton et al. (2003, 2010) reported microscopic bubble textures of pumice clasts from the $232 \mathrm{AD}$ eruption in detail, based on SEM analysis of thin sections. They used textural parameters, such as bubble number densities and bubble size distributions, to constrain the magma ascent history leading to the abrupt shift of eruption styles. Houghton et al. (2010) also conducted the macroscopic classification based on visual observation. They found that the two large dry eruptions (units $5 \mathrm{a}, 5 \mathrm{~b}$, and 6 ), particularly unit 6 , were characterized by an increase in tube pumice and highly vesiculated pumice (Fig. 4b of Houghton et al. 2010). An increase in tube pumice toward the flow stage has been confirmed in other caldera-forming eruptions (Taddeucci and Wohletz 2001; Polacci et al. 2003). Although its formation mechanism is debated, the stratigraphic difference of abundances of tube pumice may indicate the temporal and spatial variations of shear deformation in conduit flow (Bouvet de Maisonneuve et al. 2009; Dingwell et al. 2016; Ohashi et al. 2018). Therefore, for the purpose of a direct comparison with the data of Houghton et al. (2010), we use pumice clasts from Taupo plinian fall deposits (unit 5a), Taupo ignimbrite (unit 6), and those in the fall deposits of Hatepe plinian (unit 2; a sustained, 
moderately powerful plinian phase). We do not use samples from the intra-plinian flow (unit 5b).

\section{Field sampling}

Samples from units 2, 5a, and 6 were collected from different outcrops (Fig. 1a). The fall deposits of Hatepe plinian (unit 2) were sampled at location A about $25 \mathrm{~km}$ away from vent 1 . This outcrop shows the whole sequence of the $232 \mathrm{AD}$ Taupo eruption and has been investigated by previous studies (Walker 1980, 1981). The thickness of unit 2 at location $A$ is about $150 \mathrm{~cm}$ (Fig. 1b).

To investigate the transition from a plinian fall to ignimbrite, we conducted detailed sampling of unit $5 \mathrm{a}$ at location $\mathrm{B}$, which is about $20 \mathrm{~km}$ away from vent 3 . This outcrop, located on the main dispersal axis of unit 3 , is outside the area covered by intra-plinian flow (unit $5 b$ ). In location B, the Taupo plinian fall deposit (unit 5a) can be divided into two sub-units according to sharp changes in color, content of lithic clasts, and grain size of pumice clasts: (1) a fine lower unit $(30 \mathrm{~cm})$ containing brown pumice clasts and rich in lithic fragments, and (2) a coarse upper unit $(180 \mathrm{~cm})$, characterized by vesiculated white pumice clasts and poor lithic content (Fig. 1b). We collected pyroclasts from the bottom to the top of unit $5 \mathrm{a}$ at $20-\mathrm{cm}$ intervals. Only the lowermost section was $10-\mathrm{cm}$ thick. Pumice clasts from the Taupo ignimbrite (unit 6) were collected at location C $48 \mathrm{~km}$ away from vent 3.

For measuring the distribution of vesicularity, Houghton and Wilson (1989) and Shea et al. (2010) recommend using at least 100 pumice clasts with the diameter range from 16 to $32 \mathrm{~mm}$. This range is also recommended by Mitchell et al. (2018), who measured bulk vesicularities of a wide range of pumice clasts from the Hatepe plinian (unit 2).

In this study, we collected 100 clasts with a diameter of $16-32 \mathrm{~mm}$ in unit 2, but due to the restriction of the baggage weight, we could not bring a sufficient number of clasts for units $5 \mathrm{a}$ and 6 . When the number of pumices with $16-32 \mathrm{~mm}$ was less than 100 , we compensated the measurements with pumice clasts of other sizes. We used 25 clasts from the $8-16 \mathrm{~mm}$ size range for unit $5 \mathrm{a}$, and 32-64 mm clasts for unit 6.

\section{Methods}

Textural analyses using a digital stereo microscope with low-angled ring illumination (DSM-LaRI)

We cut pumice samples along the plane parallel to the visually identified direction of bubble elongation. A standard cutting machine (MC-110, MARUTO) was used. Images of the cutting surfaces were taken with a digital stereo microscope (VHX-1000, Keyence) at

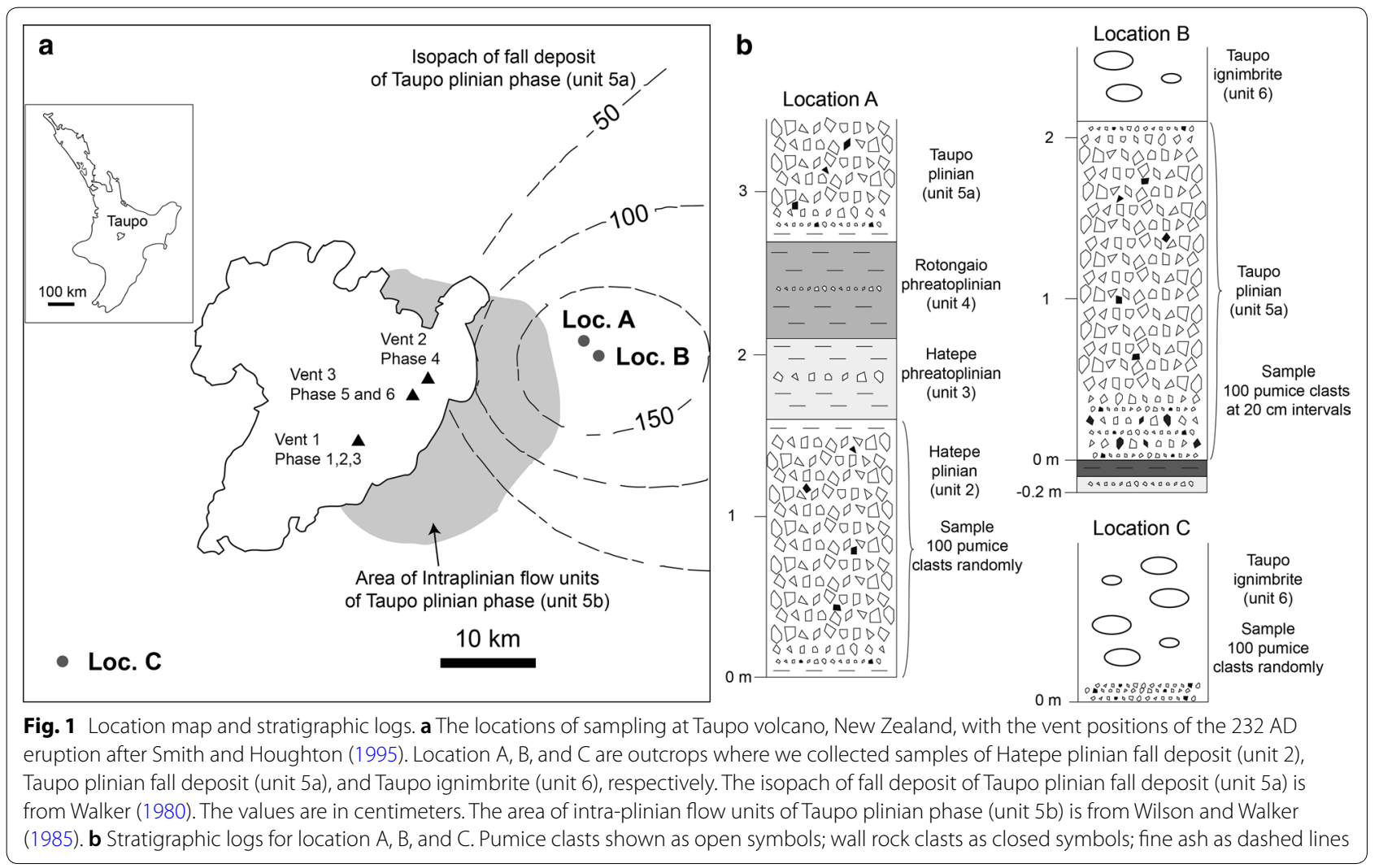


Table 1 Spatial resolution of DSM-LaRI and SEM

\begin{tabular}{|c|c|}
\hline Method & $\begin{array}{l}\text { Spatial } \\
\text { resolution } \\
(\mu \mathrm{m} / \text { pixel })\end{array}$ \\
\hline DSM-LRI 20x & 9.5 \\
\hline SEM $1 \times\left(08 \_07\right)$ & 28.2 \\
\hline SEM $1 \times\left(08 \_18\right)$ & 16.6 \\
\hline SEM 1× (10_26) & 12.0 \\
\hline SEM $1 \times\left(06 \_40\right)$ & 21.7 \\
\hline SEM $40 x$ & 2.32 \\
\hline SEM $100 \times$ & 0.934 \\
\hline SEM $500 \times$ & 0.185 \\
\hline
\end{tabular}

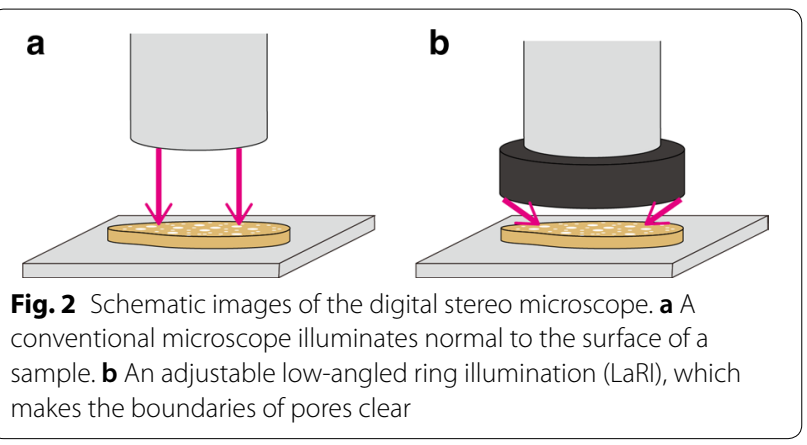

a magnification of $20 \times$. The spatial resolution of an image taken by the DSM was $9.5 \mu \mathrm{m} /$ pixel (Table 1 ). The boundaries between a bubble and matrix glass were not visible using the conventional illumination normal to the surface (Figs. 2a and 3a). We illuminated the surface obliquely (Fig. 2b) using a low-angled ring light attachment (VH-K20, Keyence). We set the illumination angle at the lowest of the adjustable range $\left(10-50^{\circ}\right.$ from horizontal according to the personal communication with the manufacturer). The low-angled illumination generated shadows inside the bubbles and clarified their boundaries (Fig. 3b). We adjusted the light intensity to optimize the contrast between bubbles and matrix glasses. The light intensity measured with an illuminometer (HP-881D, HoldPeak) was $4000 \pm 500$ lux.

Image processing was conducted by Matlab. First, we converted the images taken by the DSM-LaRI to grayscale images and then transformed them into binary images. The ring illumination from the lens's circumference made the center of the image brighter than the edges. To recognize bubbles correctly in the binarization, we used an adaptive threshold algorithm, which computes the threshold of brightness values locally (Bradley and Roth 2007). Second, bubbles smaller than 20 pixels (equivalent to a circular area with a radius of $0.024 \mathrm{~mm}$ ) were erased as they were indistinguishable from noise in brightness values. Bubbles contacting with the image borders were also removed because they do not retain their original shapes. Third, the trace holes of crystals, which were made in the cutting process, were removed manually. The manual removal of trace holes takes about 20 s per image.

Figure 3c shows an example of the obtained binary images. Large bubbles have been segmented correctly, but small bubbles less than a few tens of microns have been uncaptured. Raising the sensitivity of the adaptive threshold of brightness helps to recognize those small bubbles but fails in segmenting bubbles. We empirically determined the optimal value of the sensitivity, so that we can segment large bubbles correctly and recognize small bubbles as much as possible. Nevertheless, the image processing regarded small bubbles immediately adjacent to the large bubbles as a matrix phase. This method should be applied to analyze relatively large bubbles (larger than tens of microns) in a sample.

We used the binary images to measure each bubble area, which we converted to the equivalent bubble radius, $R$ (the radius of a circle whose area is equal to that of the bubble). Each bubble was approximated by an ellipse having the same center of gravity (Fig. 3d). The shape of the fitted ellipse was used for calculating the bubble deformation degree (Taylor 1934).

$$
D=(a-c) /(a+c)
$$

where $a$ and $c$ are the major and minor axes of the ellipse, respectively. $D=0$ corresponds to a circle and $D=1$, an extremely elongated one. The bubble deformation degrees within pyroclasts have been measured for estimating capillary number during magma ascent (Rust et al. 2003; Rust and Cashman 2007).

As a calibration of the DSM-LaRI technique, we measured the size of holes drilled in a test sample. The error in the measurement of the hole radius by DSM-LaRI was less than $0.01 \mathrm{~mm}$. See Additional file 1 for more information.

\section{Thin-section imagery}

We performed microscopic analyses of thin sections by SEM to verify the new method by the DSM-LaRI. We selected four representative pumice samples from unit 5a, which exhibited distinct bubble characteristics (Fig. 4). Thin sections were made from the same cutting surfaces captured by the DSM-LaRI. We followed the imaging technique described by Shea et al. (2010). Backscattered electron images of the thin sections were collected with an electron probe microanalyzer (EPMA) with a field emission gun (JEOL, JXA-8530F Plus at the Earthquake Research Institute of the University of Tokyo) at an accelerating voltage of $12 \mathrm{kV}$. The whole image of 

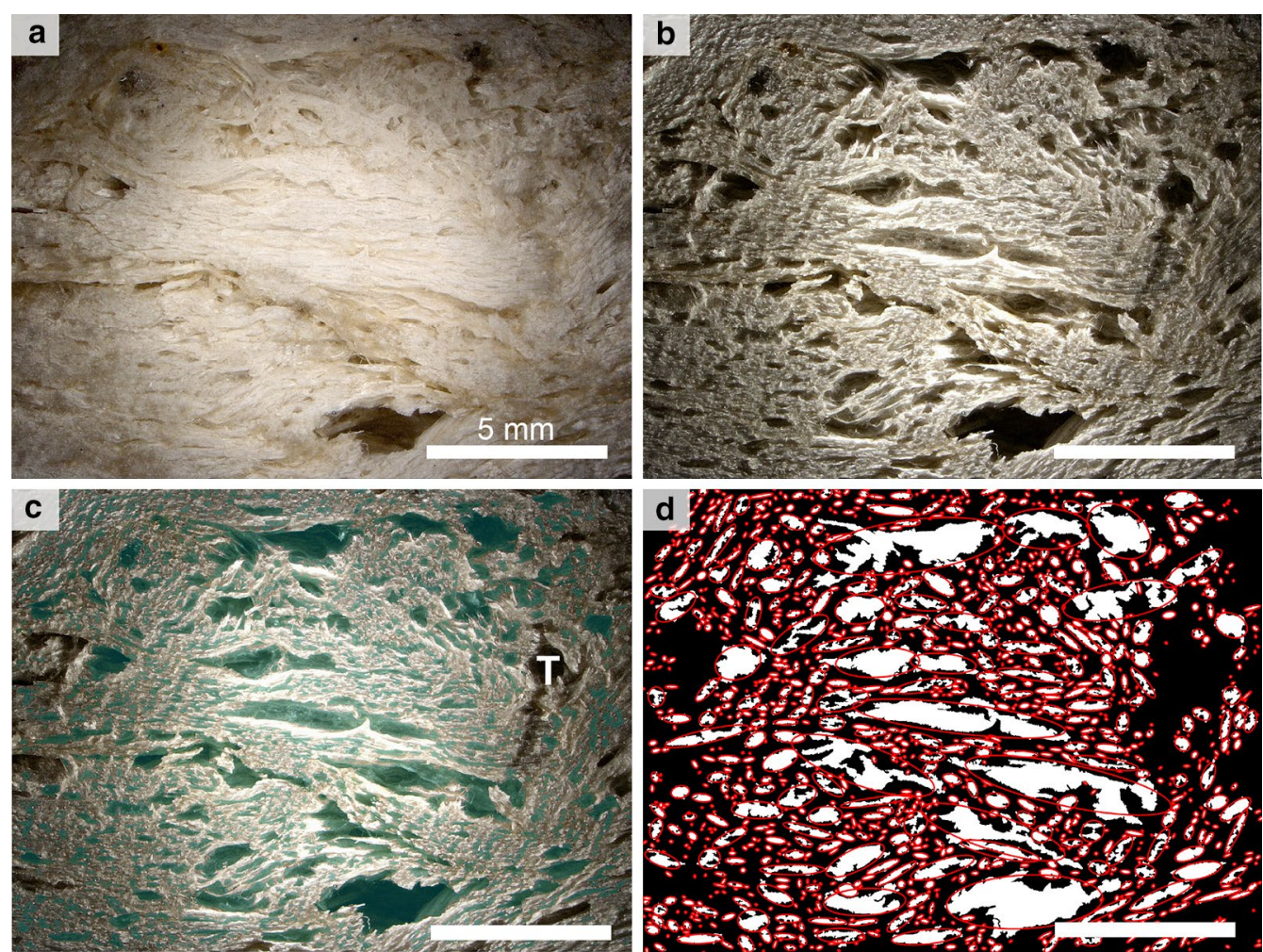

Fig. 3 Digital stereo microscope images. Images a with the conventional light (Fig. 2a) and $\mathbf{b}$ with the adjustable low-angled ring illumination (Fig. 2b). c A green/transparent binary image overlying the image of $\mathbf{b}$. The green-colored parts are bubbles recognized by image processing. ' $T$ ' indicates trace holes of crystals. $\mathbf{d}$ A white/black binary image of the recognized bubbles. Ellipses fitting the bubbles are shown in red. The white bar shows a 5-mm scale in all panels

the thin section was made by connecting several images at a magnification of $40 \times$. For each thin section, 15 images, which were scanned at a range of magnifications from $1 \times$ to $500 \times$, were transformed into binary images by setting grayscale thresholds, with spatial resolutions ranging from 0.1 to $30 \mu \mathrm{m} /$ pixel (Table 1). Bubble walls in pumice are often too thin to be resolved, and are sometimes destroyed while making thin sections. Missing bubble walls were reconstructed by drawing them manually. The final binary images were analyzed by FOAMS (Shea et al. 2010) to obtain bubble sizes and bubble deformation degrees.

\section{D analyses by X-ray CT}

We performed 3D imaging by the X-ray CT with two resolutions. We selected nine pumice clasts from each unit (units 2, 5a, 6) to be measured by low-resolution X-ray CT (METROTOM 800, Carl Zeiss, at Saitama Industrial Technology Center). A sample shaped in a cuboid $\left(\sim 1000 \mathrm{~mm}^{3}\right)$ was mounted on the rotational stage in the X-ray CT system and rotated $360^{\circ}$ in steps of $0.45^{\circ}$ (800 projections). The configuration used for the tomographic scan was a tube voltage of $130 \mathrm{kV}$, a tube current of $60 \mu \mathrm{A}$, and a voxel size with edge lengths in each direction of $8 \mu \mathrm{m}$. The sizes of scanned images are shown in Additional file 1: Table A1. The spatial resolution of the X-ray scanner (METROTOM 800) is not enough to resolve very thin glass walls (a few microns). To reconstruct missing bubble walls, we adopted the marker-controlled watershed algorithm (Meyer and Beucher 1990). The detailed procedure of the image processing using Fiji (Schindelin et al. 2012) is described in Additional file 1.

To resolve the fine textures, we also performed highresolution X-ray CT for some samples by SkyScan 1272 (Bruker) at Saitama Industrial Technology Center. As the X-ray from this CT scanner is too weak to penetrate a dense pumice clast, we selected a few highly vesiculated pumices from those analyzed by the low-resolution X-ray CT. The samples were cut into small cuboids with a square base of about $1 \mathrm{~mm} \times 1 \mathrm{~mm}$ and a height of about $2 \mathrm{~mm}$. They were imaged by a $50 \mathrm{kV}-200 \mu \mathrm{A}$ energy source and rotated $360^{\circ}$ in steps of $0.1^{\circ}$ (3600 projections). The spatial resolution is $0.45 \mu \mathrm{m} /$ voxel. Threedimensional images were reconstructed by the NRecon software. The method of image processing of bubbles is the same as that for the low-resolution X-ray CT. 

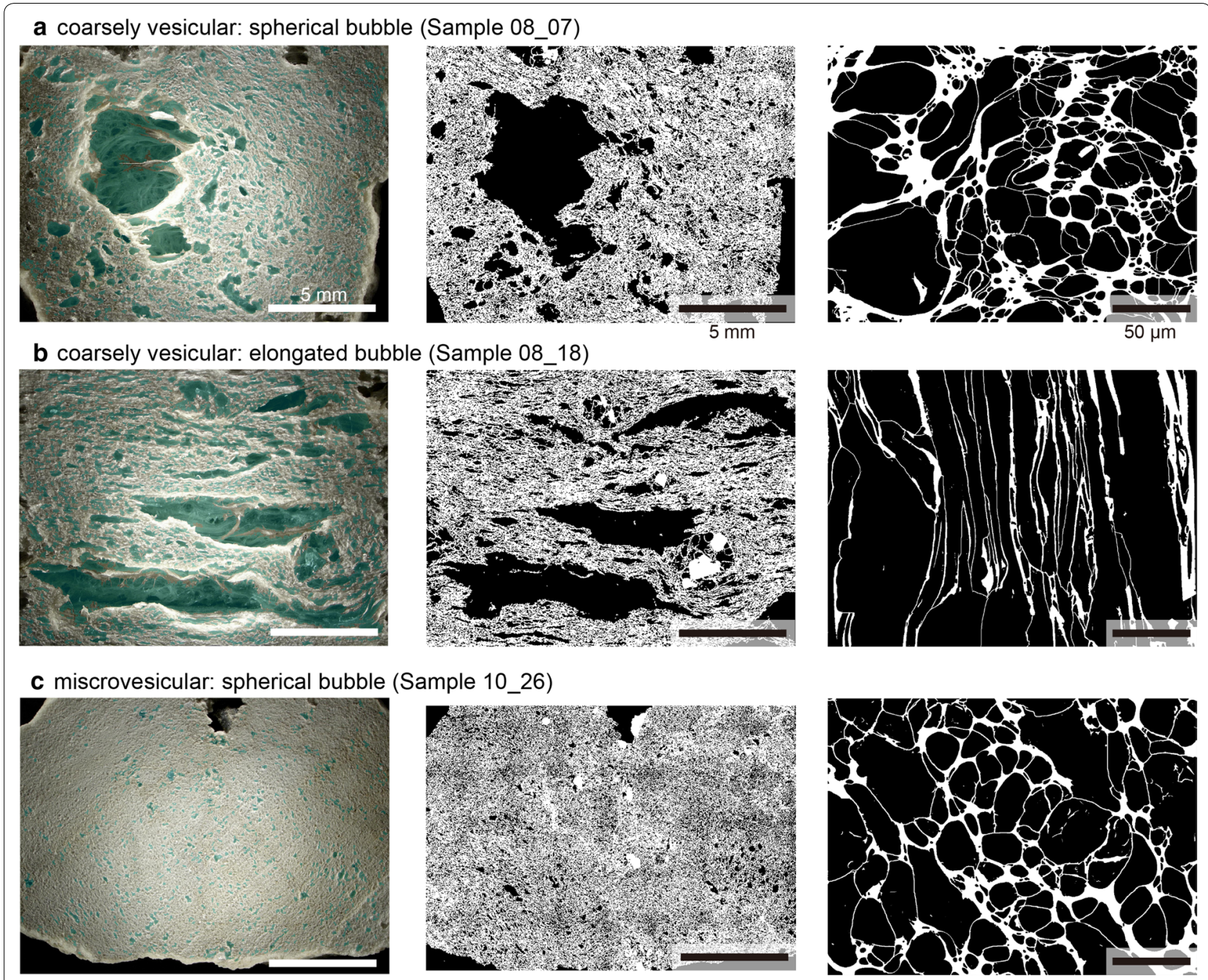

d miscrovesicular: elongated bubble (Sample 06_40)
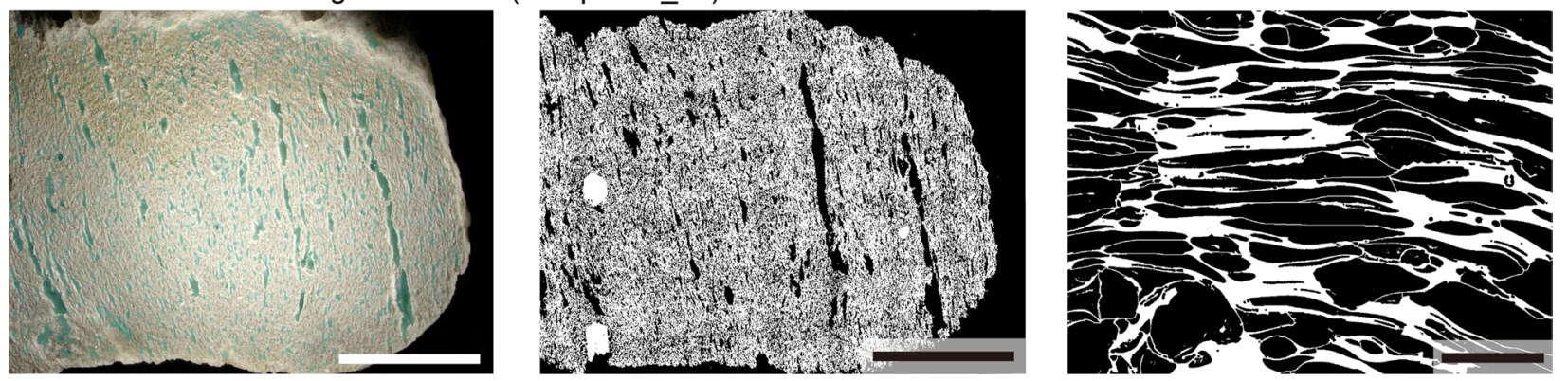

Fig. 4 Representative pumice samples form unit 5a (Taupo plinian fall deposit). Images of the representative samples (Table 2). The left column is the binary images of the DSM-LaRl like the one in Fig. 3c. The middle and right are the SEM images with bubbles appearing black. The scale is common within each column

\section{Results}

Representative samples

Figure 4 shows binary images with DSM-LaRI and processed binary images with SEM of four representative pumice samples listed Table 2. As Houghton et al. (2010) described, there is a wide range of bubble textures in the 232 AD Taupo eruption. The images of the DSM-LaRI (left column in Fig. 4) are slightly different from those by 
Table 2 Summary of bubble textures of the representative samples

\begin{tabular}{|c|c|c|c|c|c|c|}
\hline Sample & Unit & Vesicularity $^{\mathrm{a}}(\%)$ & $\begin{array}{l}\text { 2D surface vesicularity } \\
\text { by DSM-LaRI }{ }^{\mathbf{b}}(\%)\end{array}$ & Texture & $\begin{array}{l}\text { Edit distance } \\
\text { for } R\end{array}$ & $\begin{array}{l}\text { Edit } \\
\text { distance } \\
\text { for } D\end{array}$ \\
\hline 08_07 & $5 a$ & 77.8 & 26.3 & Coarsely vesicular: spherical bubble & 2.42 & 2.16 \\
\hline 08_18 & $5 a$ & 78.1 & 36.4 & Coarsely vesicular: elongated bubble & 4.26 & 3.29 \\
\hline 10_26 & $5 a$ & 73.1 & 6.0 & Microvesicular: spherical bubble & 0.77 & 2.26 \\
\hline $06 \_40$ & $5 a$ & 78.2 & 12.2 & Microvesicular: elongated bubble & 1.15 & 4.37 \\
\hline
\end{tabular}

${ }^{a}$ Measured by the Archimedes method (Houghton and Wilson 1989)

b Bubbles are recognized by DSM-LaRI

SEM because we have polished the cutting surface when making thin sections.

The $2 \mathrm{D}$ surface vesicularities measured by the DSMLaRI are shown in Table 2. They are $41.7-67.1 \%$ less than the 3D vesicularities measured by the Archimedes method (Houghton and Wilson 1989).

For the representative samples, Fig. 5 shows the area fractions of bubbles having the individual ranges of the equivalent bubble radius. The inset histograms show the data of all bubbles. The apparent difference between the histograms from DSM-LaRI and SEM is that the former data lack small bubbles $(<0.05 \mathrm{~mm})$ seen in the later data. As explained in the methods, the analysis with the DSM has been optimized for the bigger bubbles and the DSM resolution of $9.5 \mu \mathrm{m}$ is not sufficient to recognize thin bubble walls (microns).

The main histograms show the distribution only for bubbles larger than $0.05 \mathrm{~mm}$ to compare the results in the same bubble size. The difference between DSMLaRI and SEM seems to be subtle in microvesicular pumices (Fig. 5c, d), but non-negligible in coarsely vesiculated pumices (Fig. 5a, b). To quantify the difference, we adopted an edit distance, $d_{\text {edit }}$ proposed for a coarsely vesicular: spherical bubble

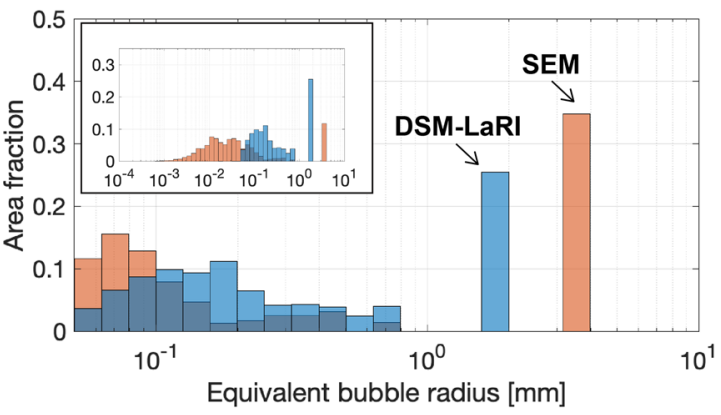

C microvesicular: spherical bubble

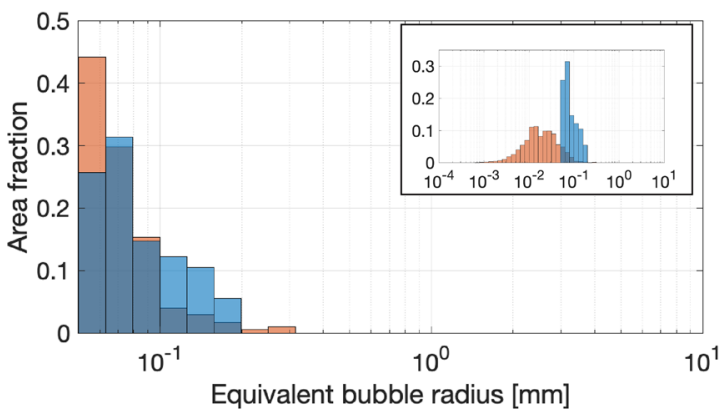

b coarsely vesicular: elongated bubble

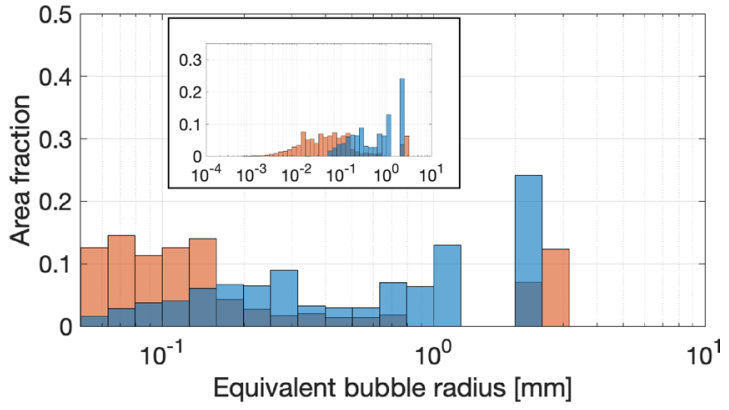

d microvesicular: elongated bubble

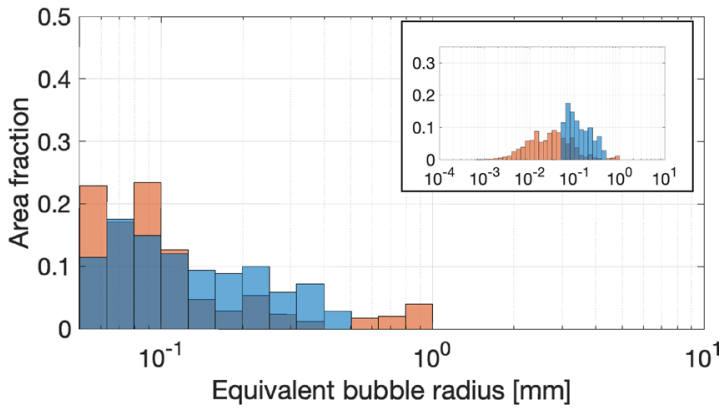

Fig. 5 Histograms of equivalent bubble radius. Histograms of equivalent bubble radius $(R)$ versus area fraction obtained with the DSM-LaRI (blue) and the SEM (red). The mainframes include only bubbles of $R>0.05 \mathrm{~mm}$, while the inset graphs show the area fraction distribution of all the bubbles captured by the SEM. a Sample 08_07. b Sample 08_18. c Sample 10_26.d Sample 06_40 
comparing two histograms (Cha and Srihari 2002). It is defined as follows:

$$
d_{\text {edit }}=\sum_{i=1}^{n}\left|\sum_{j=1}^{i}\left(H_{\text {DSM-LRI }}(j)-H_{\text {SEM }}(j)\right)\right|,
$$

where $H_{\mathrm{DSM}-\mathrm{LRI}}(j)$ and $H_{\mathrm{SEM}}(j)$ are the area fractions of the $j$-th bin in the DSM-LaRI histogram and in the SEM histogram, respectively, and $n$ is the total number of the bins. The edit distance represents the minimum amount of necessary movements to transform one histogram to the other. For a fixed number of bins, the greater the edit distance is, the more dissimilar the two histograms are. Table 2 shows the edit distances between the DSMLaRI and SEM histograms. The coarsely vesiculated samples show larger edit distances than the microvesicular samples.

In all the four cases, the biggest bubble measured from the DSM-LaRI data is smaller than that from the SEM data, which is caused by the over-segmentation of large bubbles. Although the low-angled illumination is expected to darken bubbles' interiors, it sometimes creates bright parts within bubbles, especially inside large bubbles (Fig. 4a, b). The image analysis identifies the illuminated internal parts as bubble walls and segments a single bubble into smaller ones. We believe the SEM images to exhibit more reliable bubble shapes, representative of the sample sections.

The area fraction of bubbles with the equivalent radii of $<0.1 \mathrm{~mm}$ is systematically smaller with the DSM-LaRI compared to the SEM. This difference is particularly noticeable in the coarsely vesiculated samples (Fig. 5a, b). In the microvesicular pumice samples, bubbles between 0.05 and $0.1 \mathrm{~mm}$ are surrounded by much smaller bubbles (Fig. 4c, d). Therefore, these 0.05-0.1-mm-diameter bubbles are slightly easier to detect without resolving bubble walls. On the other hand, in the coarsely vesiculated pumice samples, those bubbles often appear to contact each other, and bubble walls are thinner (Fig. 4a, b). These contacting bubbles are recognized as a single, larger one in the DSM-LaRI; while, the SEM can resolve bubble walls and separate them. For the above reason, the edit distance of the bubble radius histograms from DSMLaRI and SEM is larger for coarsely vesiculated pumice samples than for the microvesicular samples.

Figure 6 shows the area fractions of the bubble deformation degrees. As in Fig. 5, the main graphs show the results for bubbles larger than $0.05 \mathrm{~mm}$. Compared to the bubble size distributions (Fig. 5), the bubble elongation distributions are similar between the DSM-LaRI and a coarsely vesicular: spherical bubble

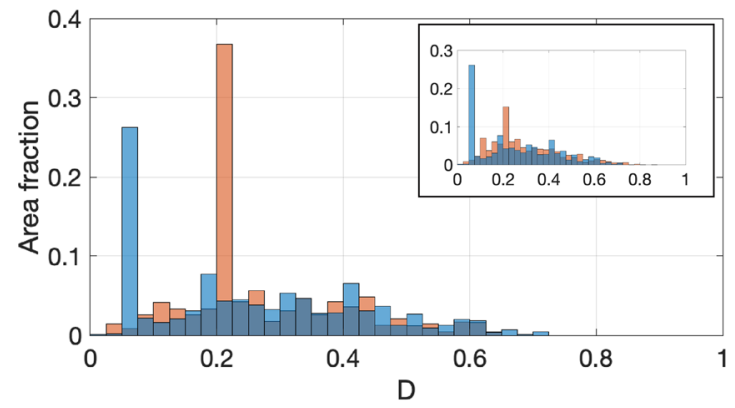

C microvesicular: spherical bubble

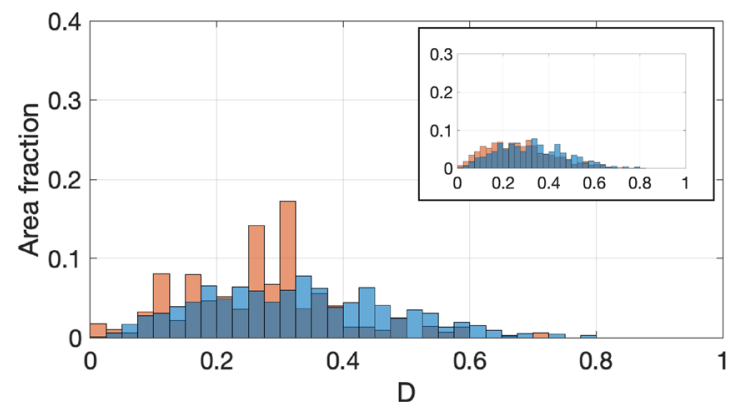

b coarsely vesicular: elongated bubble

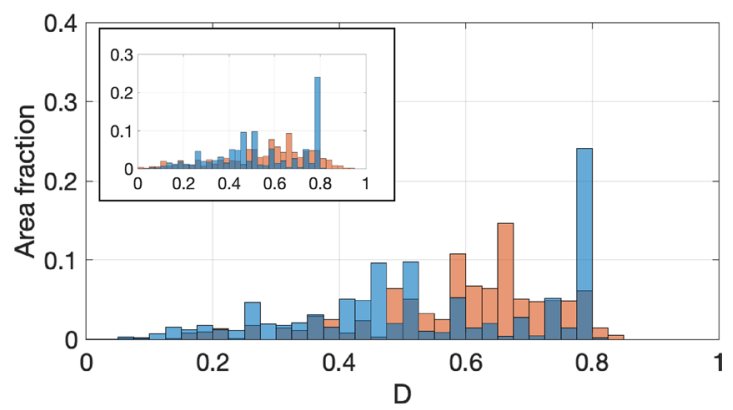

d microvesicular: elongated bubble

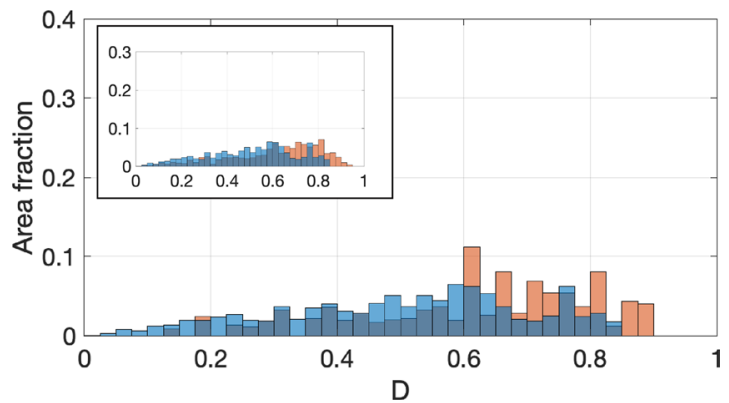

Fig. 6 Histograms of bubble deformation degree. Histograms of bubble deformation degree versus area fraction obtained with the DSM-LaRI (blue) and the SEM (red). The mainframes include only bubbles of equivalent radii larger than $0.05 \mathrm{~mm}$, while the inset graphs show the area fraction distribution of all the bubbles captured by the SEM. a Sample 08_07. b Sample 08_18. c Sample 10_26. d Sample 06_40 
SEM data. The edit distances are shown in Table 2. It is noted that we can reasonably compare the edit distances calculated for the same set of bins. In the samples with elongated bubbles (Fig. 6b, d), the DSM-LaRI data tend to shift to the smaller values of $D$ than the SEM data, which again is due to the over-segmentation of long bubbles in the DSM-LaRI image processing (Fig. 4b, d).

The X-ray CT makes it possible to measure $D$ for highly deformed bubbles in 3D. Figure 7 shows the relationships between $D$ and bubble size obtained by the three imaging methods for the same pumice sample from Taupo ignimbrite (unit 6). With an increasing bubble radius $(R), D$ also increases, which is similar between the DSM-LaRI and low-resolution X-ray CT. We can check the validity of these results using the high-resolution X-ray CT images. The cross-sectional image of the high-resolution X-ray $\mathrm{CT}$ shows thin bubble walls of a few microns (Fig. 7c). The relationship between $D$ and $R$ shows an almost constant value of $D(\sim 0.65)$ for bubbles with $0.025<R<0.15 \mathrm{~mm}$ (Fig. 7c; green area). On the other hand, the DSM-LaRI and the low-resolution $\mathrm{X}$-ray CT exhibit the smaller $D(0.4<D<0.65)$ in the corresponding range of $R$ (Fig. 7a, b). These results suggest that the DSM-LaRI and the low-resolution X-ray CT may not accurately measure the shape of bubbles with $R<0.15 \mathrm{~mm}$.
The accuracy of the DSM-LaRI also depends on the deviation of the cutting surface from the true direction of bubble elongation. This problem is described in Additional file 1.

\section{Statistical characterization of bubble textures in the outcrop scale}

As described earlier, by measuring bubble sizes and shapes through the stratigraphic sequence, we can infer the temporal and spatial variations in magma-filled conduit flow. An underlying assumption is that magmas in individual fragments have ascended along different portions of a conduit, and that they preserve the corresponding deformation histories in their bubble textures. The above assumption is based on a common understanding of laminar flow mechanics. To discuss the dynamics in a conduit, we define textural parameters characterizing a pumice clast.

We employ the average bubble radius and the average bubble deformation degree obtained by the DSM-LaRI for each pumice clast. First, we use sufficiently large bubbles $(R>0.15 \mathrm{~mm})$ for the DSM-LaRI resolution (Fig. 7). Second, we derive a weighted average, biased to larger $(>\sim 0.5 \mathrm{~mm}$ ) bubbles. Namely, the average bubble radius, $\bar{R}$, and the average bubble deformation degree, $\bar{D}$, are given by:

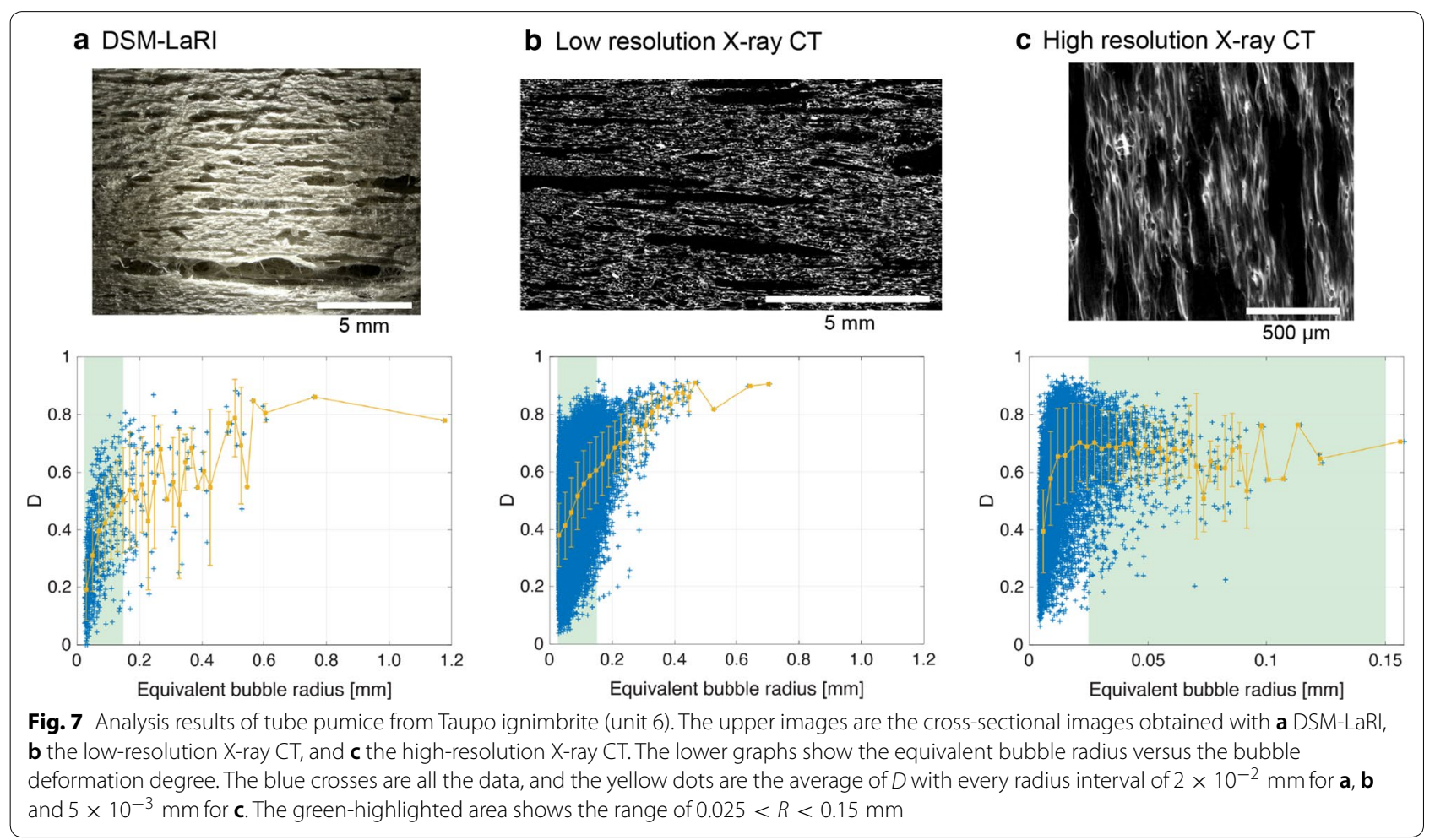




$$
\begin{aligned}
& \bar{R} \equiv \frac{\sum R_{i} A_{i}}{\sum A_{i}}, \\
& \bar{D} \equiv \frac{\sum D_{i} A_{i}}{\sum A_{i}},
\end{aligned}
$$

where $R_{i}, D_{i}$, and $A_{i}$ are the equivalent bubble radius, the bubble deformation degree, and the bubble area, respectively, of the $i$-th bubble in one pumice clast measured by the DSM-LaRI.

Figure 8 shows the relationships between $\bar{R}$ and $\bar{D}$ in units $2,5 \mathrm{a}$, and 6 . The data points corresponding to the representative samples (Figs. 4, 5, 6 and Table 2) are indicated with images. We can see no systematic correlation between $\bar{R}$ and $\bar{D}$ in the samples from the 232 AD Taupo eruption. It also demonstrates no apparent clustering.

Figure 9 shows the histograms of $\bar{R}$ and $\bar{D}$ in units 2, $5 \mathrm{a}$, and 6 , as well as the abundances of pumice types reported by Houghton et al. (2010). Although we analyzed the pumice clasts in unit $5 \mathrm{a}$ at $20-\mathrm{cm}$ intervals, we found no stratigraphic change in bubble textures $(\bar{R}$ and $\bar{D})$. Therefore, we show the sum of all the sub-layers in unit 5a in Fig. 9c. The numbers of the analyzed samples are 100 for units 2 and 6, and 1100 for unit 5a. The measurement results by the DSM-LaRI are consistent with the visual observation by Houghton et al. (2010). Units $5 \mathrm{a}$ and 6 include large bubbles, which leads to their broader size distributions than unit 2 . The histogram of $\bar{D}$ in the Taupo ignimbrite (unit 6) is markedly different from the other plinian fall units. The highest peak in unit 6 lies at $0.5<\bar{D}<0.58$, and the distribution is broad from 0.28 to 0.73 . On the other hand, the plinian fall units 2 and 5 a are mono-disperse with a peak of around $\bar{D}=0.35$, which corresponds to less elongated bubbles. The arithmetic means and standard deviations of $\bar{R}$ and $\bar{D}$ are summarized in Table 3 .

\section{Discussion}

Integrated methodology for measuring bubble textures

Imaging by the DSM-LaRI provides quantitative bubble textures in the scale of $>0.05 \mathrm{~mm}$. It is not easy to obtain similar amounts of data by the existing 2D approach making thin sections or the $3 \mathrm{D}$ approach by X-ray CT because of the long preparation and acquisition time. On the other hand, the developed method with DSM-LaRI cannot resolve microscale bubbles separated by very thin walls. Measuring a wide range of bubble sizes is necessary for accurate number density and size distribution of bubbles. The bubble number density can be converted into the decompression rate in an explosive eruption (Toramaru 2006), and the bubble size distribution is useful to infer the nature of nucleation and/or coalescence events (Klug and Cashman 1994).

For the SEM and X-ray CT analyses, it is necessary to select a small number of representative clasts from each stratigraphic unit. Previous studies analyzed the apparent density and selected several clasts representing low, moderate, and high vesicularity groups (Carey et al. 2009; Shea et al. 2010; Houghton et al. 2010). The selection was based on the assumption that the eruption had lateral vesiculation gradients in a conduit (Shea et al. 2012). When considering the lateral variations of shearing in a conduit (Polacci et al. 2003), the DSM-LaRI analysis will provide the bubble elongation dataset useful for the selection of representative clasts containing spherical, moderately, and highly elongated bubbles. They may have come through different paths with different shear deformation histories in a conduit and recorded the
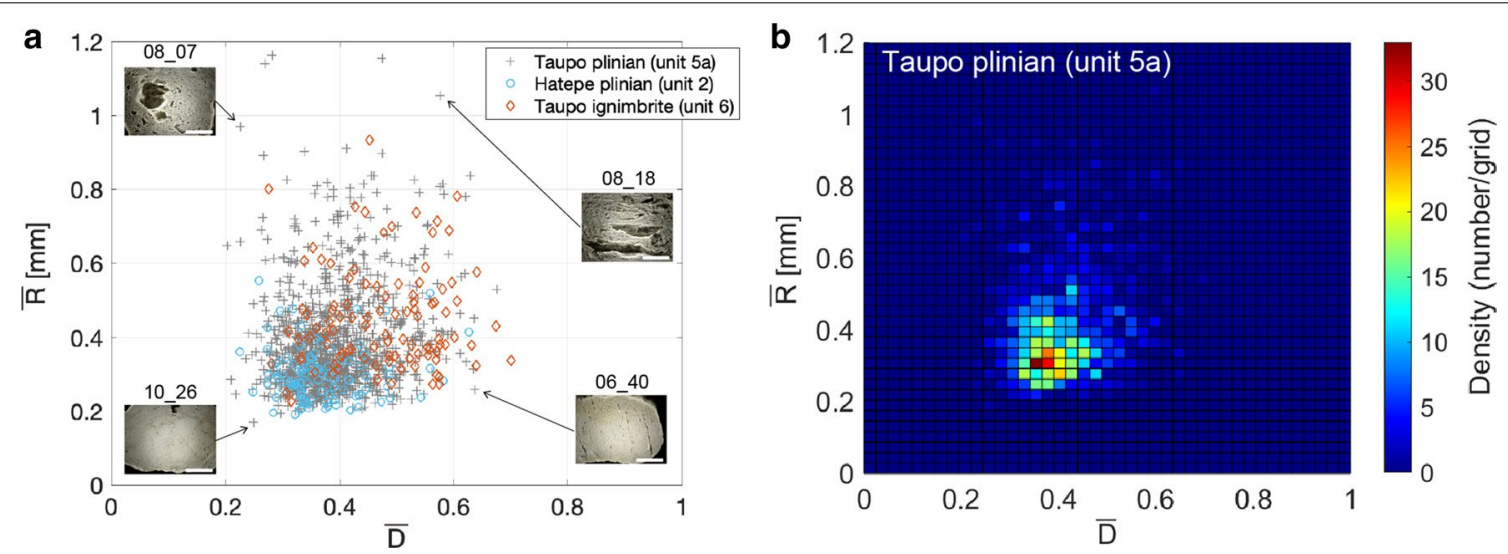

Fig. 8 Heterogeneous bubble textures. a Plot of the average bubble radius $\bar{R}$ against the average bubble deformation degree $\bar{D}$ for all measured clasts from the 232 AD Taupo eruption. Inset images show the cross sections of the representative samples shown in Figs. 4, 5, 6 and Table 2. $\mathbf{b}$ The number density of crosses in a shown by colors 


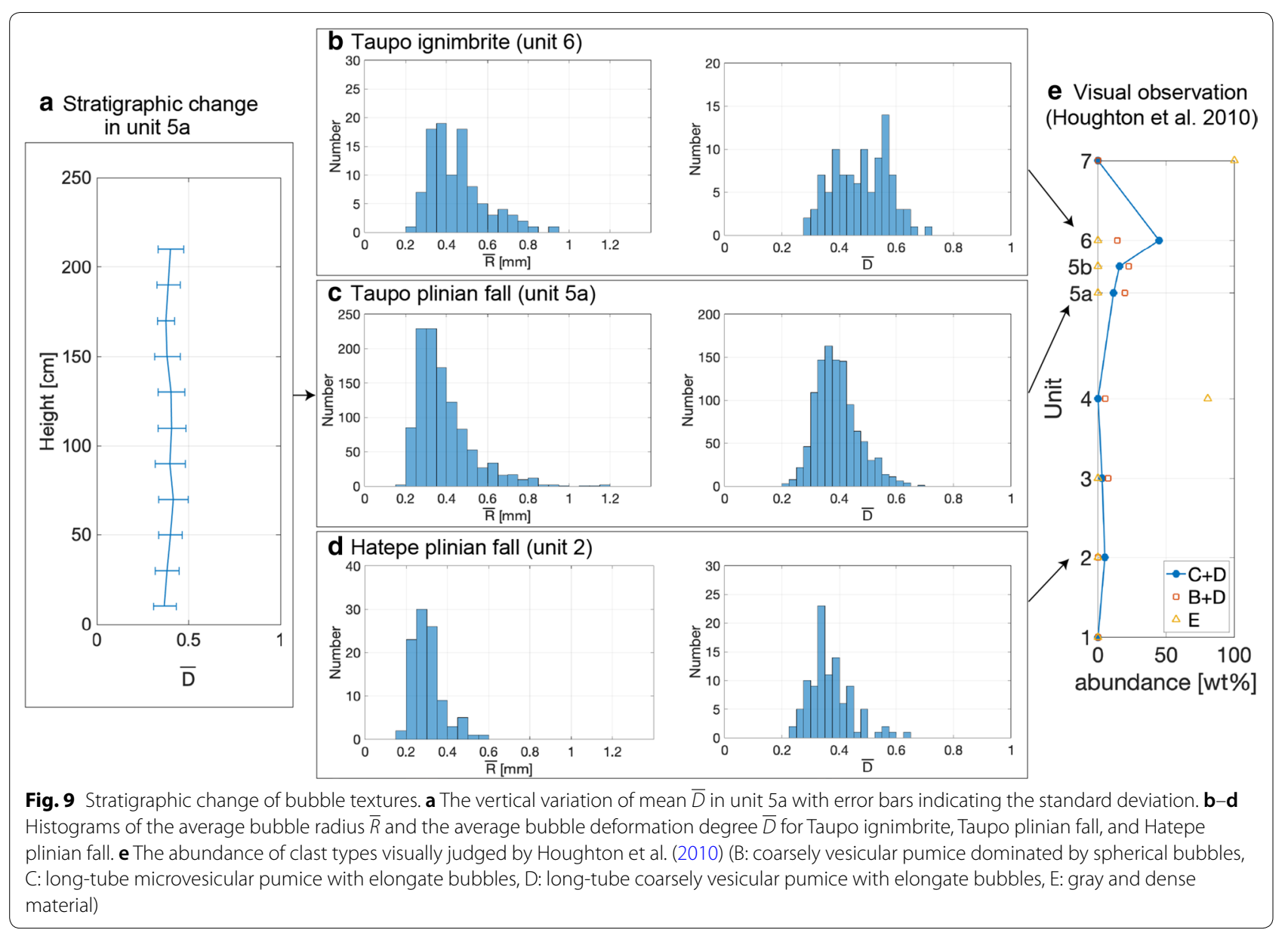

Table 3 Arithmetic means and standard deviations of $\bar{R}$ and $\bar{D}$

\begin{tabular}{llllll}
\hline Unit & Mean $\bar{R}(\mathbf{m m})$ & $\operatorname{Std} \bar{R}(\mathbf{m m})$ & Mean $\bar{D}$ & $\operatorname{Std} \bar{D}$ & $\begin{array}{l}\text { Mean } \\
\text { vesicularity } \\
(\%)\end{array}$ \\
\hline 2 & 0.303 & 0.075 & 0.369 & 0.074 & 78.6 \\
$5 a$ & 0.388 & 0.139 & 0.392 & 0.074 & 78.8 \\
6 & 0.452 & 0.139 & 0.477 & 0.097 & 88.2 \\
\hline
\end{tabular}

Mean arithmetic mean, Std standard deviation

${ }^{a}$ Measured by the Archimedes method (Houghton and Wilson 1989)

corresponding textures in various scales and shapes. The methodology integrating the DSM-LaRI with the SEM and X-ray analyses could contribute to the investigation of lateral variations of magma ascent.

\section{Textural heterogeneities and implications for magma ascent}

We have quantified the heterogeneous bubble textures of the pumice clasts from the $232 \mathrm{AD}$ Taupo eruption and the textural transition from the plinian fall deposits to the ignimbrite (Fig. 9). We will now discuss the development of these heterogeneous textures in terms of bubble size and bubble elongation.

The data obtained using the DSM-LaRI demonstrate that $\bar{R}$ increases from units 2 to 5 a and more to 6 (Table 3). Post-fragmentation bubble expansion could be a key factor during explosive volcanic eruptions (e.g., Mitchell et al. 2018). Mitchell et al. (2018) performed a detailed investigation of pumice bulk density variations over a size range between 4 and $128 \mathrm{~mm}$. They focussed their study on the Hatepe eruption (unit 2), revealing that bulk density markedly decreased as clast sizes exceeded $32 \mathrm{~mm}$. Although most pumice clasts analyzed in our study are less than $32 \mathrm{~mm}$, pumice clasts might have expanded in the pyroclastic flow (unit 6) during transport and emplacement because pumices were kept at a temperature sufficiently high to allow viscous growth for longer in the pyroclastic flow than in the eruption column. The increase of mean vesicularity from units $5 \mathrm{a}$ to 6 is correlated with the increases of $\bar{R}$ (Table 3). However, bubbles in unit 6 are more elongated than unit $5 \mathrm{a}$, 
though post-fragmentation expansion tends to return a deformed bubble to a spherical shape. Pumice clasts, particularly those with deformed bubbles, have fully connected porosities (Spieler et al. 2004; Okumura et al. 2009; Mueller et al. 2011; Colombier et al. 2017). Based on the above considerations, post-fragmentation expansion may have had minimal effect on bubble textures of pumice in the Taupo ignimbrite. A possible error that changes bubble size from units 5 a to 6 is the direction of the cutting surface of a pumice. In this study, we cut a pumice clast in a direction parallel to bubble elongation, which apparently increases a measured bubble size. This effect may be remarkable in unit 6 whose bubbles are relatively elongated. The increase in $\bar{R}$ might have also been caused by bubble coalescence during magma ascent and/ or the initial bubble size at the conduit inlet. Ultimately, the cause of the change in bubble size requires further study.

The data of DSM-LaRI, as well as that of Houghton et al. (2010), show the increase of tube pumice, composed of highly elongated bubbles, from the fallout phases to the flow stage (Fig. 9). Alternatively, an increase in tube pumice abundance within the flow phase has been observed in the Minoan eruption deposits (Taddeucci and Wohletz 2001). Previous studies attributed the formation of tube pumice to the increasing rate of simple shear at the conduit walls (Taddeucci and Wohletz 2001; Polacci et al. 2003; Dingwell et al. 2016). This interpretation explains the coexistence of tube pumice and pumice with spherical bubbles. However, it is still unknown why tube pumice is rare in plinian falls but abundant in ignimbrites that are generally thought associated with wider conduits. The conduit radius for unit 6 was numerically estimated to be 500-600 m (Legros et al. 2000). Supposing a parabolic velocity profile and the same ascent velocity between the plinian fall phase and ignimbrite phase, the average shear rate in the ignimbrite phase should have been smaller than that in the plinian fall phases. Nevertheless, a lot of tube pumices are found in the ignimbrite. The relation between the tube pumice formation and the conduit radius needs to be investigated in the future. The current results from analyzing a large number of samples ( $>100$ samples) will enable us to link the dispersion of the bubble elongations to the conduit-scale flow field for each phase of an eruption. In addition to that, the current method based on DSM-LaRI can statistically test the proportions of various textures to determine their relative volumes without sampling bias, leading to a better understanding of conduit processes.

\section{Future work}

There is room for improvement in the image acquisition process of the DSM-LaRI method. The current method cannot resolve bubbles glass walls smaller than the DSM resolution of $9.5 \mu \mathrm{m}$. Even if we raise the magnification of the lens, it is difficult to resolve them because the cutting surface is rough and the contrast is not sharp between bubbles and glasses. If we could cut a pumice clast more smoothly and illuminate at shallower angles, we could prevent the unexpected illumination of bubble interiors even for microscale bubbles. The image processing of the DSM-LaRI method can also be improved. In the present technique, bright parts inside bubbles, especially large bubbles, are recognized as bubble walls, which results in over-segmentation. This problem could potentially be solved by improving algorithms, with further analysis.

The main advantage of the DSM-LaRI is that it provides us with a large number of digital images from several hundred pyroclasts, which will be useful for developing a statistical analysis method for characterizing disparate sub-units with an eruption deposit. Similar approaches have been developed to characterize volcanic ash particles (e.g., Liu et al. 2015; Avery et al. 2017). For example, Shoji et al. (2018) used a machine learning method to classify ash particles into several clusters, which correspond to eruption styles. The application of the machine learning technique for bubble textures will contribute to the classification of eruption styles and improve our understanding of vesiculation processes in a conduit. An efficient image acquisition technique is essential for this approach.

\section{Conclusions}

We measured bubble textures from unpolished cutting surfaces of pumice using a digital stereo microscope with low-angled ring illumination (DSM-LaRI), which produces a good luminance contrast between the flat surfaces and bubbles. The DSM-LaRI significantly reduces the time taken to measure $2 \mathrm{D}$ bubble textures compared to the conventional method with SEM. We first compared the results obtained by the DSM-LaRI with those by SEM. We found that the DSM-LaRI method provided the distributions of size and elongation of bubbles consistent with SEM data for bubbles larger than $0.05 \mathrm{~mm}$, though it could not measure microscale bubbles $(<0.05 \mathrm{~mm})$. We also performed the X-ray CT analyses and confirmed that the DSMLaRI showed reasonable bubble deformation degrees for bubbles larger than $0.15 \mathrm{~mm}$. To characterize various bubble textures in an eruption, we define the average bubble radius, $\bar{R}$, and bubble deformation degree, $\bar{D}$, for each pumice clast. Investigating the histograms of $\bar{R}$ and $\bar{D}$ for the individual eruption phases revealed the textural evolution in the 232 AD Taupo eruption. Large bubbles increased from the Hatepe plinian fall to the Taupo plinian fall, and the amount of pumice with 
large bubble deformation degrees increased from the Taupo plinian fall to the Taupo ignimbrite. The different distributions of bubble textures in each eruption phase may reflect the shift in the eruption dynamics in the conduit.

The method developed in this study provides a tool to help understand the vesiculation and deformation processes in a conduit. Furthermore, this method could be useful in statistical image analyses in the future.

\section{Supplementary information}

Supplementary information accompanies this paper at https://doi. org/10.1186/s40623-020-01320-0.

Additional file 1. Additoinal information about the calibration, the image processing, and the errors of the DSM-LaRI.

\section{Abbreviation}

DSM-LaRI: Digital stereo microscope with low-angled ring illumination.

\section{Acknowledgements}

The authors are grateful to Takeshi Hasegawa, Lydia Harmon, and Gilles Seropian for helping us collect pumice clasts in Taupo. We also thank Atsushi Yasuda and Natsumi Hokanishi for the measurement with SEM. The manuscript has been improved by the appropriate handling by T. Yamamoto, the associate editor, and constructing comments by two anonymous reviewers. The present study was supported by Grant-in-Aid for JSPS Research Fellowship 17J05094 and the Joint Usage Program of the Earthquake Research Institute, University of Tokyo (2017B01).

\section{Authors' contributions}

$\mathrm{MO}$ analyzed samples and wrote the first draft of the manuscript. MI, BK, DG, and MO carried out the field survey. MI and FM supervised the work. All authors read and approved the manuscript.

\section{Funding}

This work is supported by Grant-in-Aid for JSPS Research Fellowship 17J05094, the Joint Usage Program of the Earthquake Research Institute, University of Tokyo (2017B01), and MEXT "Integrated Program for Next Generation Volcano Research and Human Resource Development". BK acknowledges the ECLIPSE Program supported by the New Zealand Ministry for Business, Innovation and Employment.

\section{Availability of data and materials}

This paper is based on published data which are shown as references.

Ethics approval and consent to participate

Not applicable.

\section{Consent for publication}

Not applicable.

\section{Competing interests}

The authors declare that they have no known competing financial interests or personal relationships that could have appeared to influence the work reported.

\section{Author details}

${ }^{1}$ Department of Earth and Planetary Sciences, Kyushu University, Motooka, 744, Nishi-ku, Fukuoka-shi, Fukuoka 819-0395, Japan. ${ }^{2}$ Earthquake Research Institute, University of Tokyo, Yayoi, 1-1-1, Bunkyo, Tokyo 113-0032, Japan. ${ }^{3}$ Department of Geological Sciences, University of Canterbury, Private Bag 4800, Christchurch, New Zealand.
Received: 6 July 2020 Accepted: 19 November 2020

Published online: 04 December 2020

\section{References}

Avery MR, Panter KS, Gorsevski PV (2017) Distinguishing styles of explosive eruptions at Erebus, Redoubt and Taupo volcanoes using multivariate analysis of ash morphometrics. J Volcanol Geotherm Res 332:1-13. https ://doi.org/10.1016/j.jvolgeores.2017.01.010

Bouvet de Maisonneuve C, Bachmann O, Burgisser A (2009) Characterization of juvenile pyroclasts from the Kos Plateau Tuff (Aegean Arc): insights into the eruptive dynamics of a large rhyolitic eruption. Bull Volcanol 71(6):643-658. https://doi.org/10.1007/s00445-008-0250-x

Bradley D, Roth G (2007) Adaptive thresholding using the integral image. J Graph Tools 12(2):13-21. https://doi.org/10.1080/2151237X.2007.10129 236

Carey RJ, Houghton BF, Thordarson T (2009) Abrupt shifts between wet and dry phases of the 1875 eruption of Askja Volcano: microscopic evidence for macroscopic dynamics. J Volcanol Geotherm Res 184(3-4):256-270. https://doi.org/10.1016/j.jvolgeores.2009.04.003

Cha SH, Srihari SN (2002) On measuring the distance between histograms. Pattern Recogn 35(6):1355-1370. https://doi.org/10.1016/S0031 $-3203(01) 00118-2$

Colombier M, Wadsworth FB, Gurioli L, Scheu B, Kueppers U, Di Muro A, Dingwell DB (2017) The evolution of pore connectivity in volcanic rocks. Earth Planet Sci Lett 462:99-109. https://doi.org/10.1016/j.epsl.2017.01.011

Degruyter W, Burgisser A, Bachmann O, Malaspinas O (2010) Synchrotron X-ray microtomography and lattice Boltzmann simulations of gas flow through volcanic pumices. Geosphere 6(5):470-481. https://doi.org/10.1130/ GES00555.1

Dingwell D, Lavallée Y, Hess KU, Flaws A, Marti J, Nichols ARL, Gilg HA, Schillinger B (2016) Eruptive shearing of tube pumice: pure and simple. Solid Earth 7(5):1383-1393. https://doi.org/10.5194/sed-7-3053-2015

Fauria KE, Manga M, Wei Z (2017) Trapped bubbles keep pumice afloat and gas diffusion makes pumice sink. Earth Planet Sci Lett 460:50-59. https:// doi.org/10.1016/j.epsl.2016.11.055

Giachetti T, Burgisser A, Arbaret L, Druitt TH, Kelfoun K (2011) Quantitative textural analysis of Vulcanian pyroclasts (Montserrat) using multi-scale $X$-ray computed microtomography: comparison with results from $2 \mathrm{D}$ image analysis. Bull Volcanol 73(9):1295-1309. https://doi.org/10.1007/ s00445-011-0472-1

Gurioli L, Harris AJL, Houghton BF, Polacci M, Ripepe M (2008) Textural and geophysical characterization of explosive basaltic activity at Villarrica volcano. J Geophys Res Solid Earth. https://doi.org/10.1029/2007JB005328

Hiroi Y, Miyamoto T (2016) Relationship between eruptive style and vesicularity of juvenile clasts during eruptive episode A of Towada Volcano, Northeast Japan. J Volcanol Geotherm Res 325:86-97. https://doi.org/10.1016/j.jvolg eores.2016.06.009

Houghton BF, Wilson CJN (1989) A vesicularity index for pyroclastic deposits. Bull Volcanol 51(6):451-462. https://doi.org/10.1007/BF01078811

Houghton B, Carey RJ (2015) Pyroclastic fall deposits. The encyclopedia of volcanoes. Academic Press, London, pp 599-616. https://doi.org/10.1016/ B978-0-12-385938-9.00034-1

Houghton BF, Hobden BJ, Cashman KV, Wilson CJ, Smith RT (2003) Largescale interaction of lake water and rhyolitic magma during the 1.8 ka Taupo eruption, New Zealand. Geophysical Monograph Series, 140(Figure 1). AGU Publications, Washington, pp 97-109. https://doi. org/10.1029/140GM06

Houghton BF, Carey RJ, Cashman KV, Wilson CJ, Hobden BJ, Hammer JE (2010) Diverse patterns of ascent, degassing, and eruption of rhyolite magma during the 1.8 ka Taupo eruption, New Zealand: evidence from clast vesicularity. J Volcanol Geotherm Res 195(1):31-47. https://doi. org/10.1016/j.jvolgeores.2010.06.002

Kennedy BM, Wadsworth FB, Vasseur J, Schipper Cl, Jellinek AM, von Aulock FW, Hess K, Russell JK, Lavallée Y, Nichols ARL, Dingwell DB (2016) Surface tension driven processes densify and retain permeability in magma and lava. Earth Planet Sci Lett 433:116-124. https://doi.org/10.1016/j. epsl.2017.01.011 
Klug C, Cashman KV (1994) Vesiculation of May 18, 1980, Mount St. Helens magma. Geology 22(5):468-472. https://doi.org/10.1130/00917613(1994)022\%3c0468:VOMMSH\%3e2.3.CO;2

Klug C, Cashman K, Bacon C (2002) Structure and physical characteristics of pumice from the climactic eruption of Mount Mazama (Crater Lake). Or Bull Volcanol 64(7):486-501. https://doi.org/10.1007/s00445-002-0230-5

Legros F, Kelfoun K, Martí J (2000) The influence of conduit geometry on the dynamics of caldera-forming eruptions. Earth Planet Sci Lett 179(1):5361. https://doi.org/10.1016/S0012-821X(00)00109-6

Liu EJ, Cashman KV, Rust AC (2015) Optimising shape analysis to quantify volcanic ash morphology. GeoResJ 8:14-30. https://doi.org/10.1016/j. grj.2015.09.001

Meyer F, Beucher S (1990) Morphological segmentation. J Vis Commun Image Represent 1(1):21-46. https://doi.org/10.1016/1047-3203(90)90014-M

Mitchell SJ, Biass S, Houghton BF, Anderson A, Bonny E, Walker BH, Mintz BG, Turner NR, Frank D, Carey RJ, Rosenberg MD (2018) The interplay among clast size, vesicularity, postfragmentation expansion, and clast breakage: an example from the $1.8 \mathrm{ka}$ Taupo eruption. Field volcanology: a tribute to the distinguished career of Don Swanson. Geological Society of America, Boulder, p 538. https://doi.org/10.1130/2018.2538(17)

Mitchell SJ, Houghton B, Carey RJ, Manga M, Fauria KE, Jones MR, Soule SA, Conway CE, Wei C, Giachetti T (2019) Submarine giant pumice: a window into the shallow conduit dynamics of a recent silicic eruption. Bull Volcanol. https://doi.org/10.1007/s00445-019-1298-5

Mueller S, Scheu B, Kueppers U, Spieler O, Richard D, Dingwell DB (2011) The porosity of pyroclasts as an indicator of volcanic explosivity. J Volcanol Geotherm Res 203(3-4):168-174. https://doi.org/10.1016/j.jvolgeores .2011 .04 .006

Ohashi M, Ichihara M, Toramaru A (2018) Bubble deformation in magma under transient flow conditions. J Volcanol Geotherm Res 364:59-75. https:// doi.org/10.1016/j.jvolgeores.2018.09.005

Okumura S, Nakamura M, Takeuchi S, Tsuchiyama A, Nakano T, Uesugi K (2009) Magma deformation may induce non-explosive volcanism via degassing through bubble networks. Earth Planet Sci Lett 281(3-4):267-274. https ://doi.org/10.1016/j.epsl.2009.02.036

Polacci M, Papale P, Rosi M (2001) Textural heterogeneities in pumices from the climactic eruption of Mount Pinatubo, 15 June 1991, and implications for magma ascent dynamics. Bull Volcanol 63(2-3):83-97. https://doi. org/10.1007/s004450000123

Polacci M, Pioli L, Rosi M (2003) The Plinian phase of the Campanian Ignimbrite eruption (phlegrean fields, Italy): evidence from density measurements and textural characterization of pumice. Bull Volcanol 65(6):418-432. https://doi.org/10.1007/s00445-002-0268-4

Polacci M, Mancini L, Baker DR (2010) The contribution of synchrotron X-ray computed microtomography to understanding volcanic processes. J Synchrotron Radiat 17(2):215-221. https://doi.org/10.1107/S090904950 9048225

Rust AC, Cashman KV (2007) Multiple origins of obsidian pyroclasts and implications for changes in the dynamics of the 1300 BP eruption of Newberry Volcano, USA. Bull Volcanol 69(8):825-845. https://doi.org/10.1007/s0044 5-006-0111-4

Rust AC, Manga M, Cashman KV (2003) Determining flow type, shear rate and shear stress in magmas from bubble shapes and orientations. J
Volcanol Geotherm Res 122(1-2):111-132. https://doi.org/10.1016/S0377 $-0273(02) 00487-0$

Schindelin J et al (2012) Fiji: an open-source platform for biological-image analysis. Nat Methods 9(7):676-682. https://doi.org/10.1038/nmeth.2019

Shea T, Houghton BF, Gurioli L, Cashman KV, Hammer JE, Hobden BJ (2010) Textural studies of vesicles in volcanic rocks: an integrated methodology. J Volcanol Geotherm Res 190(3-4):271-289. https://doi.org/10.1016/j. jvolgeores.2009.12.003

Shea T, Gurioli L, Houghton BF (2012) Transitions between fall phases and pyroclastic density currents during the AD 79 eruption at Vesuvius: building a transient conduit model from the textural and volatile record. Bull Volcanol 74(10):2363-2381. https://doi.org/10.1007/s00445-012-0668-z

Shoji D, Noguchi R, Otsuki S, Hino H (2018) Classification of volcanic ash particles using a convolutional neural network and probability. Sci Rep 8(1):8111. https://doi.org/10.1038/s41598-018-26200-2

Smith RT, Houghton BF (1995) Vent migration and changing eruptive style during the 1800a Taupo eruption: new evidence from the Hatepe and Rotongaio phreatoplinian ashes. Bull Volcanol 57(6):432-439. https://doi. org/10.1007/BF00300987

Spieler O, Kennedy B, Kueppers U, Dingwell DB, Scheu B, Taddeucci J (2004) The fragmentation threshold of pyroclastic rocks. Earth Planet Sci Lett 226(1-2):139-148. https://doi.org/10.1016/j.epsl.2004.07.016

Taddeucci J, Wohletz KH (2001) Temporal evolution of the Minoan eruption (Santorini, Greece ), as recorded by its Plinian fall deposit and interlayered ash fow beds. J Volcanol Geotherm Res 109:299-317. https://doi. org/10.1016/S0377-0273(01)00197-4

Taylor Gl (1934) The formation of emulsions in definable fields of flow. Proc R Soc Lond 146(858):501-523. https://doi.org/10.1098/rspa.1934.0169

Toramaru A (1995) Numerical study of nucleation and growth of bubbles in viscous magmas. J Geophys Res Solid Earth 100(B2):1913-1931. https:// doi.org/10.1029/94JB02775

Toramaru A (2006) BND (bubble number density) decompression rate meter for explosive volcanic eruptions. J Volcanol Geotherm Res 154:303-316. https://doi.org/10.1016/j.jvolgeores.2006.03.027

Toramaru A (2014) On the second nucleation of bubbles in magmas under sudden decompression. Earth Planet Sci Lett 404:190-199. https://doi. org/10.1016/j.epsl.2014.07.035

Walker G (1980) The Taupo pumice: product of the most powerful known (ultraplinian) eruption? J Volcanol Geotherm Res 8(1):69-94. https://doi. org/10.1016/0377-0273(80)90008-6

Walker GP (1981) Characteristics of two phreatoplinian ashes, and their water-flushed origin. J Volcanol Geotherm Res 9(4):395-407. https://doi. org/10.1016/0377-0273(81)90046-9

Wilson CJN, Walker GPL (1985) The Taupo Eruption, New Zealand I. General aspects. Philos Trans R Soc A Math Phys Eng Sci 314(1529):199-228. https ://doi.org/10.1098/rsta.1985.0019

\section{Publisher's Note}

Springer Nature remains neutral with regard to jurisdictional claims in published maps and institutional affiliations.

\section{Submit your manuscript to a SpringerOpen ${ }^{\circ}$ journal and benefit from:}

- Convenient online submission

- Rigorous peer review

- Open access: articles freely available online

- High visibility within the field

- Retaining the copyright to your article

Submit your next manuscript at springeropen.com 